$\mathrm{T}$ актика ведения пациентов с тяжелым розацеа И.Г. Сергеева', Ю.М. Криницына, ${ }^{1}$

1 ФГАОУ ВО «Новосибирский национальный исследовательский государственный университет» 630090 , г. Новосибирск, ул. Пирогова, д. 1

2 ФГБ НУ «Институт молекулярной патологии и патоморфологии» 630117 , г. Новосибирск, ул. Тимакова, д. 2

В статье приводится 3 клинических наблюдения женщин 51, 55 и 57 лет с тяжелым течением розацеа, достигших состояния ремиссии после длительного курса системной терапии низкими дозами изотретиноина. Кумулятивная доза изотретиноина до достижения стойкой клинической ремиссии составила 46,4мг/кг веса, 17,6 мг/кг веса,

12,6 мг/кг веса соответственно. Общая продолжительность курса лечения 16, 15 и 13 мес. Сложности, связанные с субъективным восприятием пациентками своего состояния, ограничивали возможность увеличения суточной дозы изотретиноина, а отсутствие эфффекта от предшествующей терапии базовыми препаратами делало изотретиноин препаратом выбора.

Ключевые слова: розацеа, изотретиноин в форме LIDOSE.

Контактная информация: i_g_sergeeva@mail.ru. Вестник дерматологии и венерологии 2016; (5): 72 -78.

\title{
Strategy for managing patients with severe cases of rosacea
}

\author{
I.G. Sergeyeva ${ }^{1}$, Yu.M. Krinitsyna ${ }^{1,2}$
}

${ }^{1}$ Novosibirsk State National Research University

Pirogova str., 1, Novosibirsk, 630090, Russia

${ }^{2}$ Research Institute of Regional Pathology and Pathomorphology

Timakova str., 2, Novosibirsk, 630117, Russia

The article presents 3 clinical observations of women of 51, 55 and 57 years old with severe rosacea, who reached the state of remission after a prolonged course of systemic therapy with low doses of isotretinoin. Cumulative dose of isotretinoin for persistent clinical remission was $46.4 \mathrm{mg} / \mathrm{kg}$ of weight, $17.6 \mathrm{mg} / \mathrm{kg}, 12.6 \mathrm{mg} / \mathrm{kg}$ respectively. Difficulties related to the subjective perception of patients of his condition has limited the possibility of increasing daily dose of isotretinoin, and the lack of result from the previous therapy with basic medications has made isotretinoin a drug of choice.

Key words: rosacea, isotretinoin in the form of LIDOSE.

Corresponding author: i_g_sergeeva@mail.ru. Vestnik Dermatologii i Venerologii 2016; 5: 72—78. 
При тяжелом течении розацеа, характеризующемся наличием выраженной эритемы, папулезных и пустулезных высыпаний, сливающихся в бляшки, при окулярном подтипе - наличии явлений светобоязни, выраженного блефарита, эписклерита, системная терапия изотретиноином позволяет получить клиническое улучшение [1].

Изотретиноин применяется в различных дозировках, в том числе достаточно низких (5-20 мг на 1 кг массы тела в сутки), возможно неежедневное применение препарата [2]. Также обсуждаются вопросы применения минимальной поддерживающей дозы для сохранения ремиссии заболевания [3].

Длительный опыт применения изотретиноина в фрорме LIDOSE у пациентов с тяжелым течением розацеа показал эффективность низких доз изотретиноина в сложных клинических ситуациях.

\section{Клиническое наблюдение № 1}

Пациентка Т. 51 года обратилась с жалобами на высыпания на коже лица, ощущение жжения и зуда. Покраснение кожи лица периодически было с молодого возраста, на фоне климакса 2 года назад начали появляться высыпания. После курсов системной терапии метронидазолом, диосмином 600 , аскорутином, наружной терапии гелем с $1 \%$ метронидазолом, гелем демотен периодическое улучшение состояния кожи, но затем прогрессирование тяжести заболевания.

В анамнезе жизни - административная работа, двукратно проходила лечение описторхоза бильтрицидом. При обследовании биохимический анализ крови без патологии.

При осмотре в фреврале 2015 г. на коже лица распространенная эритема с очагами инфильтрации, папулами, пустулами (рис. 1, 2). Поставлен диагноз: папуло-пустулезный подтип розацеа. Учитывая тяжесть состояния и неэффрективность предшествующей терапии, пациентке назначен изотретиноин в фрорме LIDOSE в дозе 0,22 мг/кг в сутки с коррекцией сухости кожи наружным применением эмолентов. Через 1 мес. лечения наблюдали уменьшение количества папулезных и пустулезных высыпаний. Пациентка продолжала предъявлять большое количество жалоб, связанных как с основным заболеванием (покраснение кожи лица и ощущение жара), так и с применением препарата (сухость губ, кожи лица). Через 3 мес. применения изотретиноина из-за сильной головной боли пациентка самостоятельно отменила препарат, но резкое обострение заболевания послужило поводом к возобновлению терапии, и больше головная боль не появлялась.

В июле 2015 г. инфильтраты на лице полностью регрессировали, свежие высыпания появлялись очень редко и носили поверхностный характер. Доза изотретиноина была уменьшена до 0,11 мг/кг в сут-

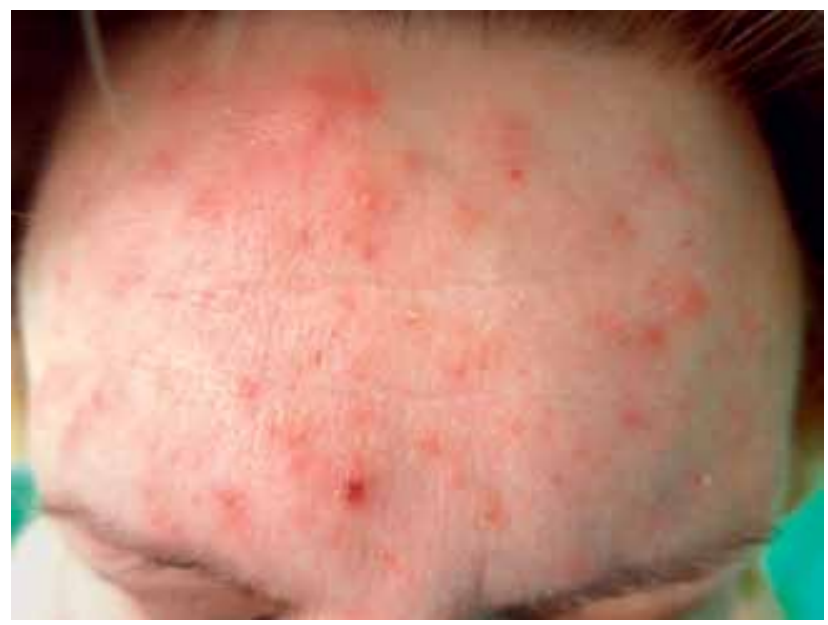

Рис. 1. Состояние кожи лба пациентки Т. 51 года с тяжелым течением розацеа

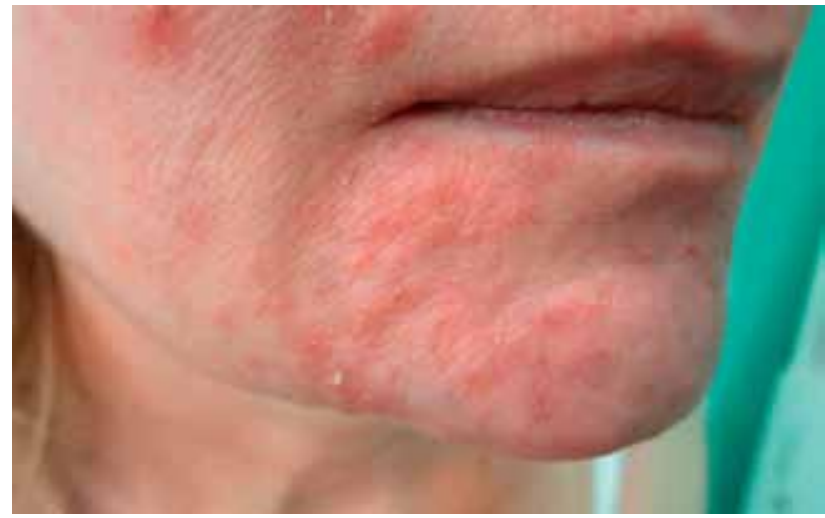

Рис. 2 Инфильтрация кожи в области подбородка пациентки Т. 51 года с тяжелым течением розацеа

ки, и лечение продолжено с постепенным уменьшением частоты приема препарата до 2 раз в неделю. В декабре 2015 г. на фоне применения изотретиноина 0,05 мг/кг в сутки появлялись высыпания на коже лица в виде зудящих эритематозных пятен, присоединение к лечению крема с 0,2\% пиритионом цинка привело к регрессу этого состояния. Даже во время применения препарата 2 раза в неделю пациентка предъявляла жалобы на сухость губ и ощущение сухости в горле.

В апреле 2016 г. полученная доза изотретиноина составила 46,4 мг/кг, на коже лица сохранялась небольшая эритема без папулезных, пустулезных высыпаний и инфильтратов (рис. 3, 4). 


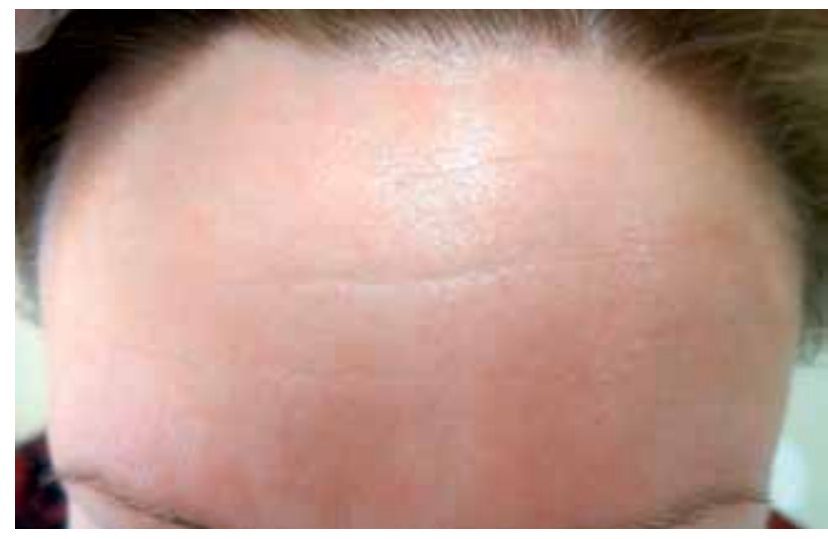

Рис 3. Состояние кожи лба пациентки Т. 51 года после курса системной терапии розацеа изотретиноином в фрорме LIDOSE

\section{Клиническое наблюдение №2}

Пациентка Г. 55 лет обратилась в октябре 2013 г. с жалобами на покраснение кожи лица и появление болезненных образований (рис. 5). Первые высыпания появились в возрасте 37 лет после операции (удаление кисты яичника), на протяжении последних 5 лет проходила лечение с диагнозом дерматит лица, получала топические глюкокортикостероиды ежедневно, итраконазол системно, короткие курсы антибиотиков (азитромицин). На протяжении последних 2 лет ежедневно пользуется бетаметазонсодержащим топическим препаратом.

Работает продавцом продуктового магазина. В анамнезе лечение описторхоза бильтрицидом, гепатит A, гипертоническая болезнь, эрозивно-геморрагический гастрит. Биохимический анализ крови: показатели в пределах нормы.

При осмотре на коже лица выраженная эритема застойно-синюшного цвета, телеангиэктазии в области щек, глубокие папулезные и пустулезные элементы. Поставлен диагноз: папуло-пустулезный подтип розацеа, тяжелое течение, стероидзависимость. Стартовый курс лечения включал системную терапию метронидазолом, наружное применение крема с 1\% метронидазолом в комбинации с мазью 0,1\% такролимусом и отменой наружного применения глюкокортикостероидов. Начало применения такролимуса сопровождалось жжением, которое прекратилось через 2 нед.

После курса терапии метронидазолом значительного улучшения состояния кожи не наблюдалось (рис. 6), дополнительно назначен изотретиноин в формe LIDOSE 0,1 мг/кг в день, наружно продолжено применение 0,1\% такролимуса. Через 2 нед. от начала применения прекратили появляться крупные папулопустулезные высыпания на коже лица. Через 3 мес. от начала лечения изотретиноином сохранялась си-

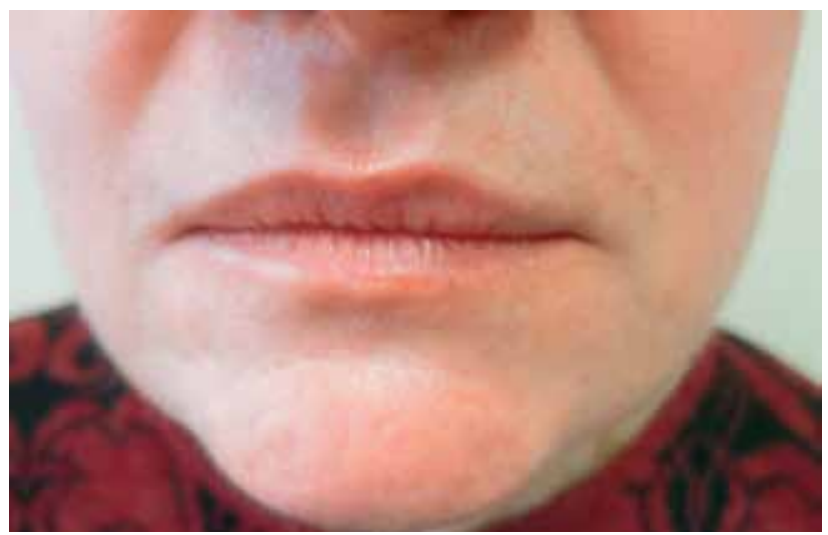

Рис Состояние кожи нижней трети лица пациентки Т., 51 года после курса системной терапии розацеа изотретиноином в форме LIDOSE

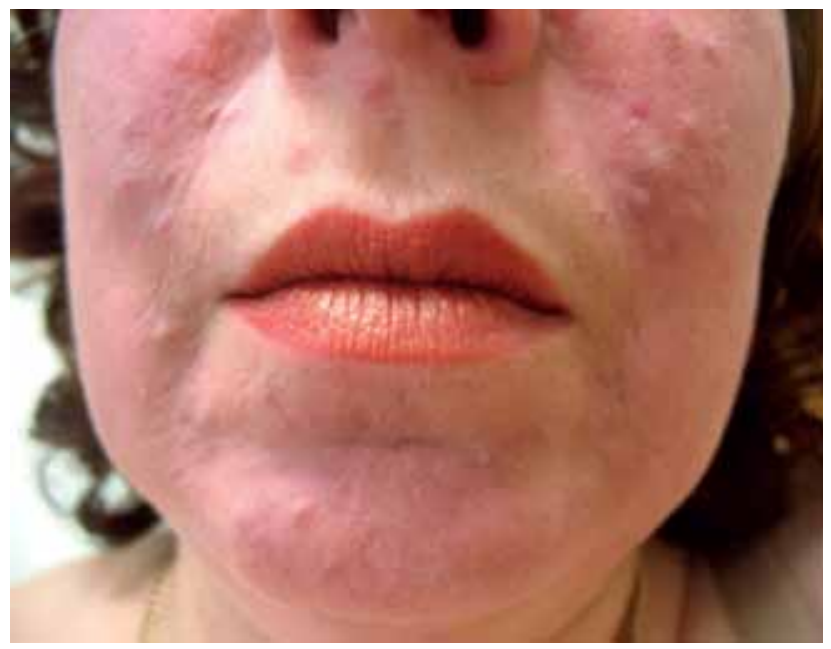

Рис. 5. Состояние кожи лица пациентки Г. 55 лет до начала терапии

нюшно-розового цвета эритема кожи лица, яркость эритемы начала уменьшаться, размеры и глубина свежих папуло-пустулезных элементов значительно уменьшились (рис. 7). Продолжение терапии до сентября 2014 г. с постепенным снижением дозы акнекутана $(0,1 \mathrm{мг/кг} \mathrm{через} \mathrm{день)} \mathrm{и} \mathrm{частоты} \mathrm{нанесения} \mathrm{такро-}$ лимуса (2 раза в неделю) привело к полному регрессу высыпаний и уменьшению выраженности эритемы, которая появлялась только при эмоциональных переживаниях. В сентябре 2014 г. такролимус был отменен, к лечению добавлен крем с $20 \%$ азелаиновой кислотой, доза изотретиноина снижена до 0,1 мг/кг в сутки 2 раза в неделю. Осмотр в феврале 2015 г.: кожа лица чистая, лечение изотретиноином законче- 


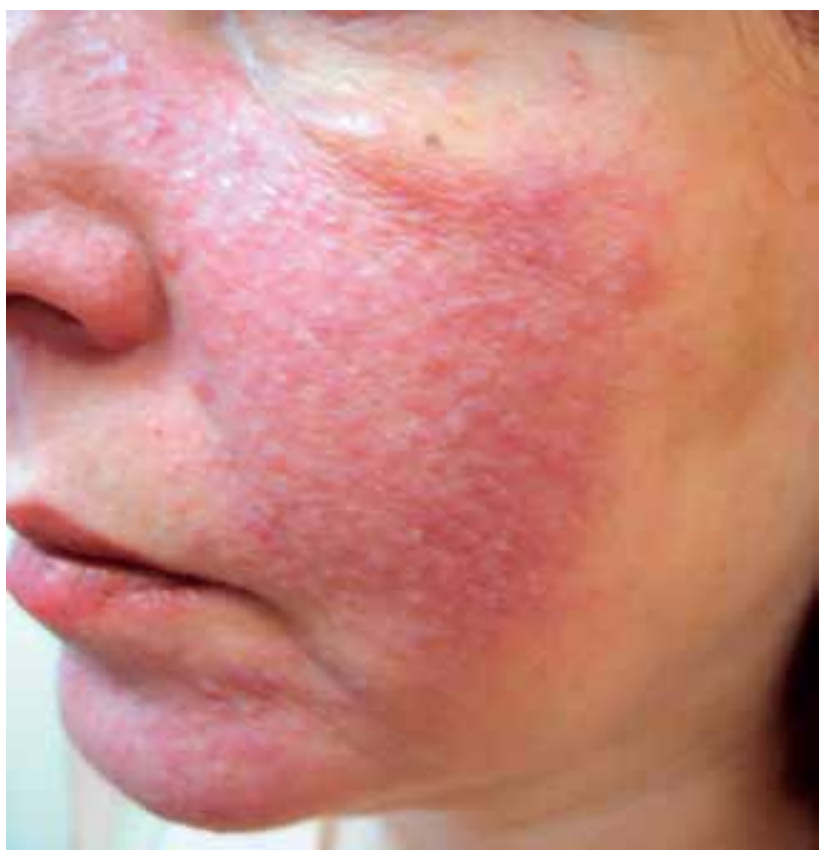

Рис. 6. Состояние кожи лица пациентки Г. 55 лет после системной терапии метронидазолом

но. До фревраля 2016 г. пациентка получала наружную просилактическую терапию $20 \%$ азелаиновой кислотой, рецидива заболевания не было (рис. 8). Общая полученная доза изотретиноина в форме LIDOSE coставила 17,6 мг/кг.

\section{Клиническое наблюдение № 3}

Пациентка А. 57 лет обратилась с жалобами на высыпания на коже лица. За 11 мес. до обращения, в январе 2014 г., после сильного стресса у пациентки развился неврит лицевого нерва, на фроне активной терапии которого появились высыпания на коже лица. На протяжении марта - октября 2014 г. получала системную терапию метронидазолом, доксициклином, наружно препараты пиритиона цинка 0,2\%, метронидазола $1 \%$ с временным улучшением. В августе 2014 г. появились отеки в области век, которые были расценены как отек Квинке, и в связи с рецидивированием отеков пациентка начала получать системную терапию преднизолоном, при попытках отмены преднизолона возникали рецидивы отеков. На момент обращения в декабре 2014 г. получала преднизолон 10 мг в сутки, наружно крем 1\% пимекролимус.

Из анамнеза: пациентка работает инженером, хронические заболевания - поверхностный гастрит, желчнокаменная болезнь (проведена холецистэктомия), цистит, узловое образование правой доли щитовидной железы. Биохимический анализ крови (глюкоза, холе-

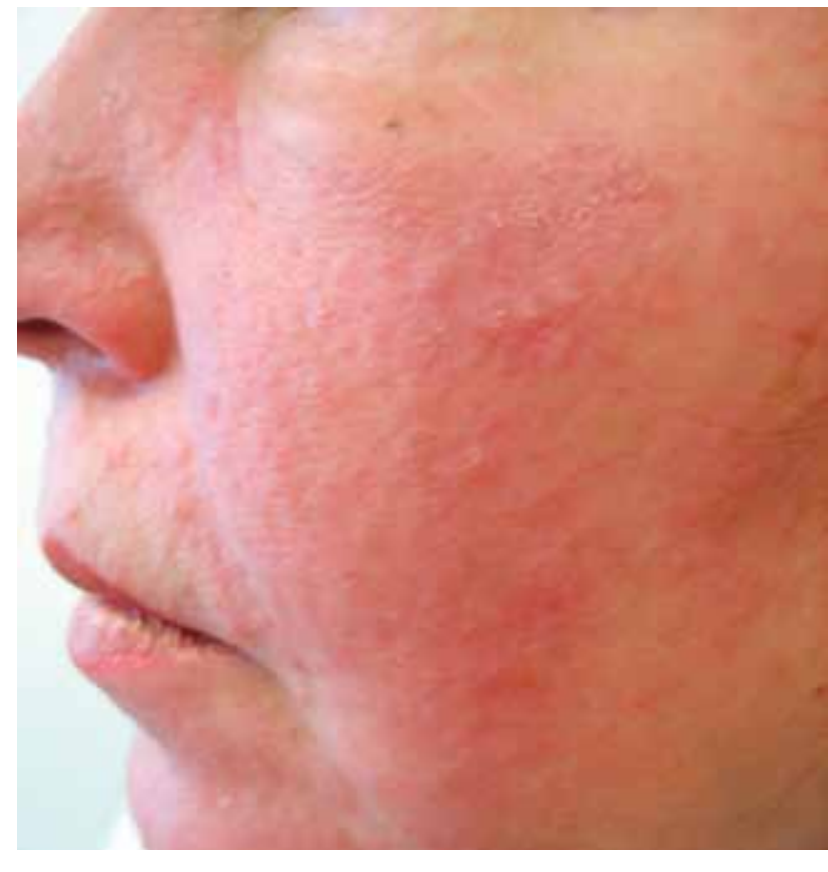

Рис. 7. Состояние кожи лица пациентки Г. 55 лет через 3 мес. системной терапии изотретиноином в фороме LIDOSE

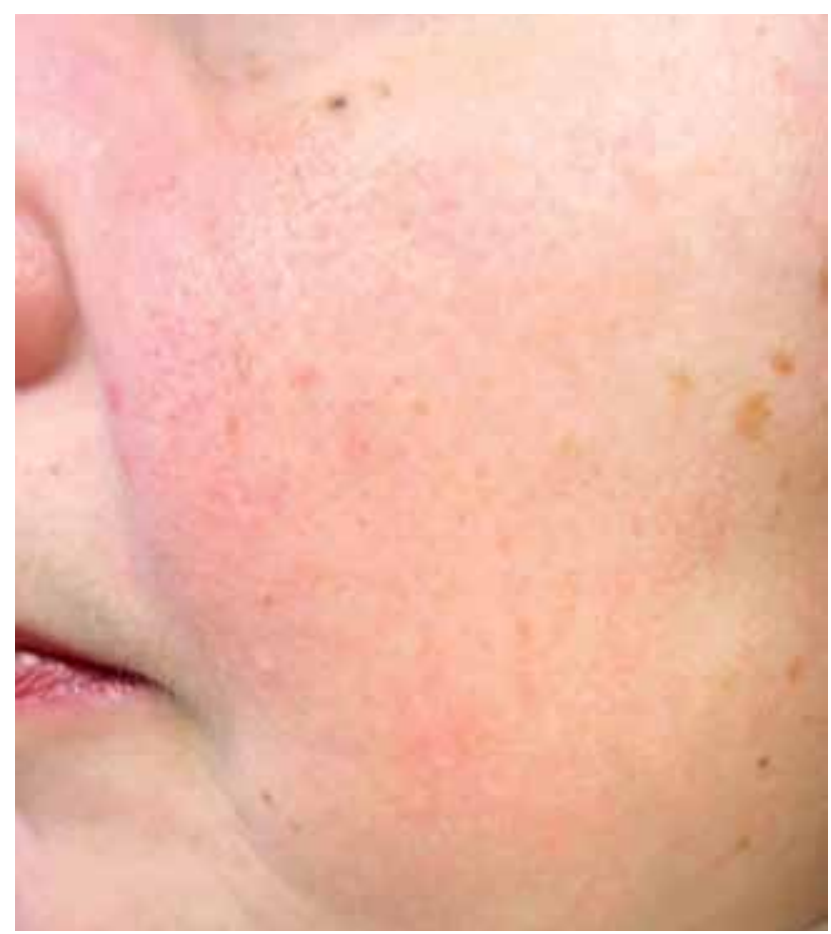

Рис. 8 Состояние кожи лица пациентки Г. 55 лет через 1 год после окончания системной терапии 
стерин, аланин-, аспартатаминотрансфрераза, билирубин, мочевина, креатинин) - в пределах нормы.

При осмотре эритема центральной части лица с множественными папуло-пустулезными высыпаниями на коже лба, носа, скул, подбородка. Поставлен диагноз: папуло-пустулезный подтип розацеа. Учитывая длительность течения заболевания и резистентность к терапии, рекомендовано: терапия изотретиноином в фороме LIDOSE (Акнекутан) в дозе 0,12 мг/кг (8 мг в сутки), продолжить терапию кремом с 1\% пимекролимусом 2 раза в день и отмена преднизолона постепенно в течение 2 нед.

После отмены преднизолона у пациентки наблюдалось выраженное обострение заболевания (рис. 9, 10). При повторном осмотре исключен диагноз отека Квинке, в области глаз развивались застойного характера отеки с выраженным скоплением серозной жидкости, связанные с инфильтрацией кожи лба и периорбитальных участков (рис. 11). У пациентки отмечалась низкая комплаентность к получаемой терапии изотретиноином, после появления отеков она повторно возобновила применение преднизолона, отменила самостоятельно изотретиноин, в апреле 2015 г. прошла курс доксициклина и наружно применение $2 \%$ клиндамицина без выраженного улучшения состояния кожи. Проконсультировалась у ревматолога для исключения системного заболевания.

В мае 2015 г. повторно проведена беседа с пациенткой о необходимости длительной ступенчатой терапии дерматоза, спланировано снижение дозы преднизолона на протяжении последующих 3 мес., рекомендовано возобновить применение изотретироина в фрорме LIDOSE в дозе 0,12 мг/кг 2 раза в неделю, наружно крем с 1\% метронидазолом. На протяжении последующих 2 мес. пациентка выполняла все рекомендации. При осмотре наблюдали уменьшение выраженности отека, эритемы, количества папуло-пустулезных высыпаний. При этом сохранялось значительное количество жалоб, связанных с низкой комплаентностью к системной терапии изотретиноином (например, пациентка описывала неприятные ощущения в виде сухости ног и переплетения «жилка за жилку или за ребро» на коже спины) в дни применения препарата, каждый эпизод покраснения лица расценивался крайне негативно с выраженными эмоциональными переживаниями. В связи с этим в сентябре 2015 г. была рекомендована биопсия кожи. Заключение гистологического исследования: морфологическая картина соответствует папулезной форме розацеа. Проведена полная отмена преднизолона, так как отеки в области глаз не появлялись, с мая 2015 г. продолжено применение изотретиноина и наружно крема с 20\% азелаиновой кислотой. Жалоб на неприятные ощущения на фоне применения изотретиноина пациентка больше не предъявляла, и в апреле 2016 г. на коже лица сохранялась только незначительная эри-

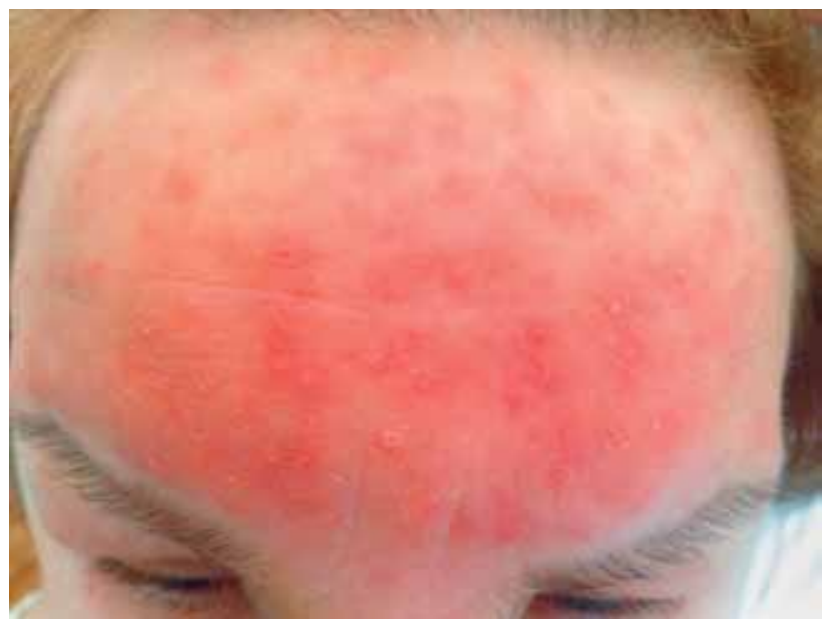

Рис. 9. Состояние кожи лба пациентки А. 57 лет до начала лечения

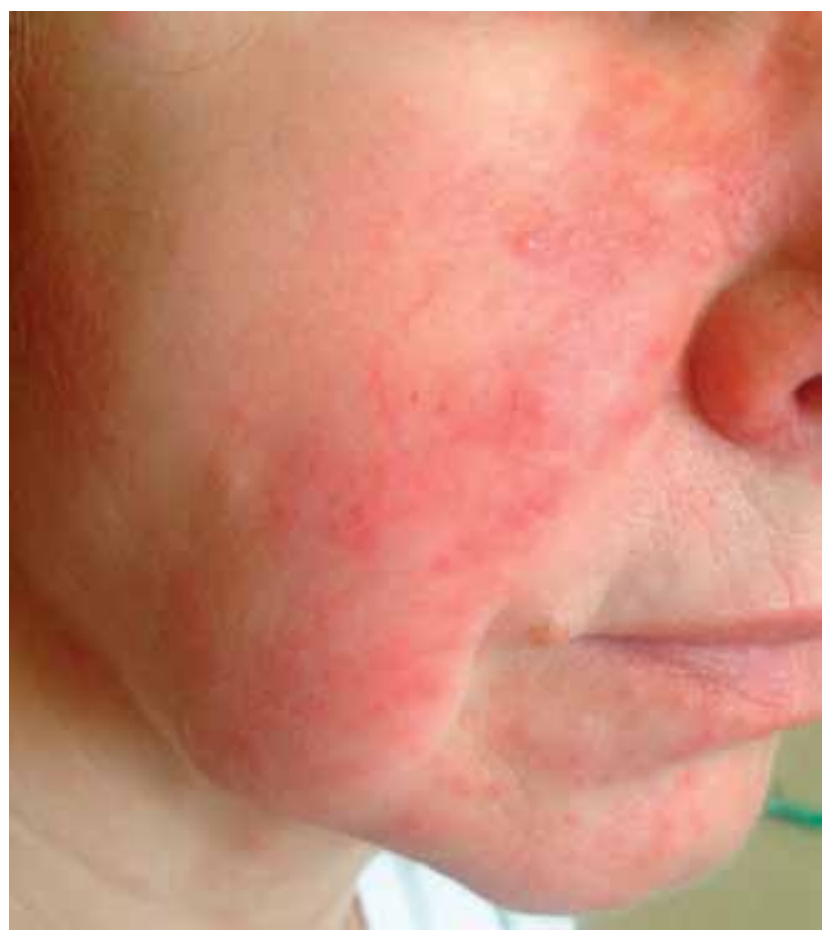

Рис. 10. Состояние кожи щеки пациентки А. 57 лет до начала лечения

тема центральной части. Папулезные и пустулезные высыпания полностью отсутствовали (рис. 12, 13). Полученная курсовая доза изотретиноина составила 12,6 мг на 1 кг массы тела пациентки. 


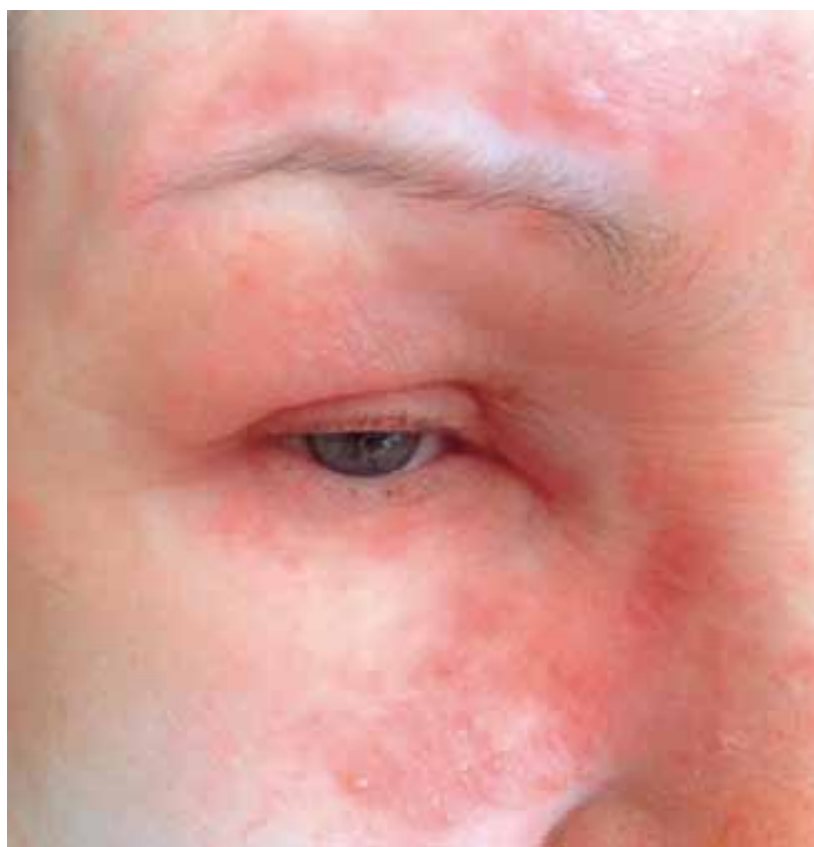

Рис. 11. Отеки в области век у пациентки А. 57 лет до начала лечения

\section{Обсуждение}

По современным представлениям ключевую роль в патогенезе розацеа связывают с процессом воспаления, которое, в свою очередь, связано с механизмами ультрафиолетового повреждения, изменением кожных сосудов, окислительными процессами в тканях [4].

В наших наблюдениях удалось достичь состояния ремиссии после длительного курса системной терапии низкими дозами изотретиноина. Кумулятивная доза изотретиноина до достижения стойкой клинической ремиссии составила 46,4, 17,6, 12,6 мг на 1 кг массы тела соответственно наблюдениям. Общая продолжительность курса лечения - 16, 15 и 13 мес.

Большое количество субъективных жалоб, предъявляемых пациентками во время терапии, было связано в первую очередь с основным заболеванием, так как у пациентов с розацеа повышен риск развития депрессии и тревожных расстройств [7]. Пациентки красочно описывали субъективные ощущения, которые появлялись во время приема изотретиноина, обычно появление этих ощущений развивалось в течение первых минут после приема очередной капсулы, что подчеркивает неврогенный характер данного состояния. Но эта ситуация значительно ограничивала возможность увеличения суточной дозы изотретиноина до значений, применяемых при лечении акне.

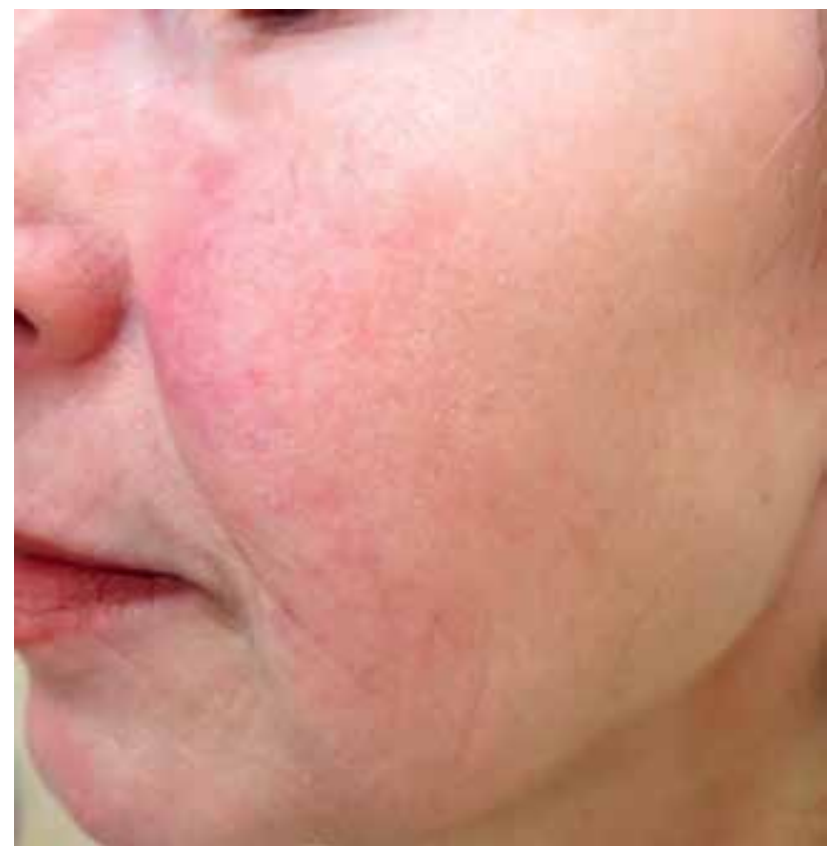

Рис. 12. Состояние кожи лица у пациентки А. 57 лет после курса изотретиноина в форме LIDOSE

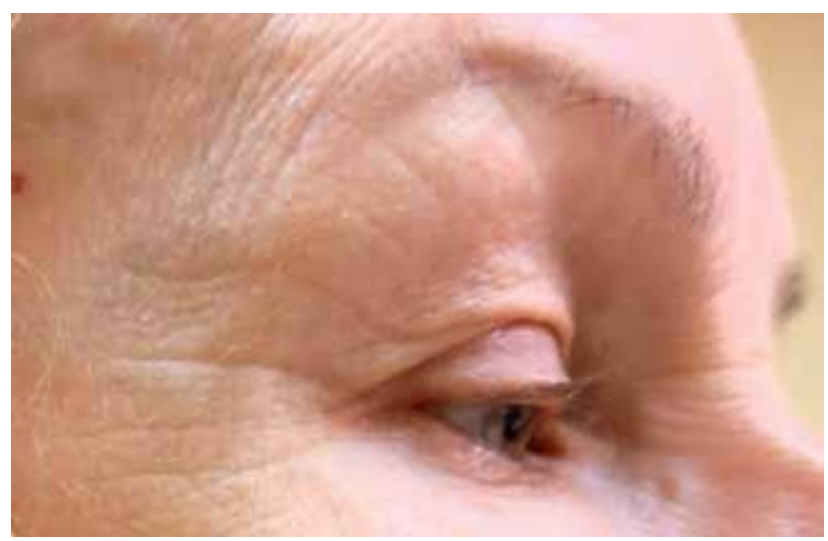

Рис. 13. Состояние кожи век у пациентки А. 57 лет после курса изотретиноина в форме LIDOSE

Несмотря на то что в литературе встречаются рекомендации применять изотретиноин при розацеа в суточной дозе 0,4-0,8 мг на 1 кг массы тела [6], в рассмотренных клинических ситуациях отсутствие эффректа от предшествующей терапии базовыми препаратами делало изотретиноин препаратом выбора и приводило к необходимости применять меньшие суточные дозы в течение более продолжительного времени для достижения стойкой клинической ремиссии. В лите- 
ратуре описано клиническое улучшение на 75\% и более от исходного уровня у $57,2 \%$ пациентов с розацеа при применении суточных доз 0,2 мг/кг на протяжении 5-7 мес., при этом длительность терапии определялась не набором курсовой дозы, как при лечении акне, а степенью выраженности клинического эфрфекта [7].
Таким образом, представленные наблюдения демонстрируют целесообразность назначения небольших доз изотретиноина у пациентов с тяжелым течением розацеа и низкой комплаентностью к терапии на протяжении длительного времени с целью получения стойкого клинического улучшения.
1. Araviyskaya E.R.. Samtsov A.V. Federalnyye klinicheskiye rekomendatsii po vedeniyu bolnykh rozatsea. Moskva; 2015. [Аравийская E.P., Самцов А.В. Федеральные клинические рекомендации по ведению больных розацеа. М; 2015.]

2. Rademaker M. Very low-dose isotretinoin in mild to moderate papulopustular rosacea; a retrospective review of 52 patients. The Australasian Journal Of Dermatology 2016; 20: $1440-0960$.

\section{Литература}

3. Sbidian E., Vicaut É., Chosidow 0. et al. A Randomized-Controlled Trial of Oral Low-Dose Isotretinoin for Difficult-To-Treat Papulopustular Rosacea. The Journal Of Investigative Dermatology 2016; 136 (6): 1124-1129.

4. Millikan $\mathrm{L}$. The proposed inflammatory pathophysiology of rosacea: implications for treatment. Skinmed 2003; 2: 43-47.

5. Egeberg A., Hansen P., Gislason G., Thyssen J. Patients with Rosacea Have Increased Risk of Depression and Anxiety Disorders: A Danish
Nationwide Cohort Study. Dermatology 2016; 232 (2): 208-213.

6. Monakhov S.A. Rozatsea (metodicheskoye posobiye dlya vrachey). M; 2016. [Монахов C.A. Розацеа (методическое пособие для врачей). M; 2016.]

7. Samtsov A.V. Gorbunov Yu.G. Izotretinoin v lechenii rozatsea. Vestn dermatol venerol 2012; (4): 102-104. [Самцов А.В., Горбунов Ю.Г. Изотретиноин в лечении розацеа. Вестн дерматол венерол 2012; (4): 102—104.]

об авторах:

И.Г. Сергеева - д.м.н., доцент, профессор кафедры фундаментальной медицины Института медицины и психологии НГУ, директор Центра постдипломного медицинского образования, Новосибирск

Ю.М. Криницына - д.М.Н., профрессор, главный научный сотрудник ФГБ НУ ИМППМ, просрессор кафредры фундаментальной медицины Института медицины и психологии НГУ, Новосибирск

\section{Конфликт интересов}

Авторы заявляют об отсутствии потенциального конфрликта интересов, требующего раскрытия в данной статье 